\title{
The Study of Effects of Olympic-Style Weightlifting Trainings on the Thickness of the Quadriceps Femoris Tendon of Athletes
}

\author{
Kenan Erdağ ${ }^{1}$, Osman Tüfekçi ${ }^{2}$ \\ ${ }^{1}$ Physical Education and Sports Department, Faculty of Education, Necmettin Erbakan University, Konya, Turkey \\ ${ }^{2}$ Özel Farabi Hospital, Konya, Turkey \\ Correspondence: Kenan Erdağı, Physical Education and Sports Department, Faculty of Education, Necmettin Erbakan \\ University, Konya, Turkey.
}

Received: March 25, 2019

Accepted: April 17, $2019 \quad$ Online Published: April 22, 2019

doi:10.11114/jets.v7i6.4171

URL: https://doi.org/10.11114/jets.v7i6.4171

\begin{abstract}
Objectives: The study aims to investigate the thickness of the quadriceps femoris tendon in Olympic-style weightlifting athletes and sedentary individuals.

Methods: The study included 25 women and 25 men Olympic-style weightlifting athletes aged 18-19 years as the study group and 25 women and 25 men sedentary individuals as the control group. In the study, the thickness of the quadriceps femoris tendon on both knees was measured by ultrasonographic imaging.

Results: The mean thickness of the quadriceps femoris tendon was significantly larger in the athletes than in the sedentary individuals. No correlation was found between the age, height, training years of the athletes and the thickness of the quadriceps femoris tendon.
\end{abstract}

Conclusion: It might be stated that Olympic-style weightlifting has a hypertrophic effect on the quadriceps femoris tendon of athletes.

Keywords: quadriceps Femoris tendon, Olympic-style weightlifting, ultrasonography

\section{Introduction}

Olympic-style weightlifting (O-sW) is an athletic sport in which athletes require to perform two Olympic-style weightlifting tasks, the snatch and clean-and-jerk (Burdett et al. 1982, Garhammer and Takano 1982). The knee extensor muscles play an important role in the execution of the snatch and clean-and-jerk movements (Garhammer 1991, 1993). During dynamic and static phases of these movements, as a result of overload on the quadriceps femoris muscle and knee joint, hypertrophic growth occurs (Kanehisa et al. 2003). The quadriceps femoris consists of four muscles which act as the major extensor apparatus for the knee. These muscles are the rectus femoris, vastus medialis, vastus lateralis, and vastus intermedius (Bencardino et al. 2000, Tuong et al. 2011, Ilan et al. 2003). These muscles of the quadriceps combine to form a common tendon insertion attaching on the patella. The quadriceps tendon (QFT) contains three layers. The most superficial layer comes out from the rectus femoris, the middle layer from the vastus lateralis and medialis, and the deepest layer from the vastus intermedius (Walton and Rothwell 1983)

There have been various studies in literature to determine the morphometry of QFT of cadavers, patients, sedentary individuals and athletes from different branches of sports (Damien et al. 2015, Todd et al. 2015, Özçakar et al. 2003, Visnes et al. 2014). It was reported that in child age groups, there was a positive correlation between age, height and body weight and the thickness of the quadriceps femoris tendon (QFTT) (Todd et al. 2015) and that QFTT was larger in men than women (Staeubli H et al. 1999) and that owing to heavy trainings, hypertrophy developed in QFTT of the athletes (Visnes et al. 2014, Pfirmann et al. 2008).

We weren't able to find any studies in literature analyzing the QFT morphometry of men (MO-sW) and women (WO-sW) O-sW athletes.

By using ultrasonographic imaging (US), the study aims to analyze QFTT of MO-sW and WO-sW along with those of sedentary individuals. 


\section{Materials and Methods}

The study included 4 groups: a group of MO-sW $(n=25)$ at a national-team level, a group of WO-sW ( $\mathrm{n}=25)$ from Turkey Olympic Preparation Centre in Konya and from the national team camp opened in Konya for the Youth European Championship to be held in Zamosc in Poland, a group of healthy sedentary men individuals with no athletic background $(n=25)$ and a group of healthy sedentary women individuals with no athletic background $(n=25)$. The demographic data and training years of the athletes in the study groups are shown in Table 1.

The inclusion criteria for the MO-sW and WO-sW were as follows: 1- training weightlifting at least for the last 2 years at a national team athlete level. 2- training weightlifting at least 5 days a week during this period with $\mathrm{O}$-sW trainings containing snatch, power snatch, clean-and-jerk, jerk push, jerk power clean, snatch pulls, clean pulls, squat front, and squat back (Badillo et al. 2006). The inclusion criteria for the sedentary individuals were as follows: 1- having no sports training before. The exclusion criteria for the athletes and the individuals were as follows: 1) Athletes and control participants with a history of tendon rupture, prior lower limb or tendon surgery, response to manual palpation or with the diagnosis of systemic inflammatory diseases such as rheumatoid arthritis and spondylarthritis.

The study was approved by the Studies Except Medicine and Medical Devices Ethics Committee in the University of Necmettin Erbakan, Meram Medical Faculty (dated 19/09/2018 and numbered 1481). All procedures followed in the study were in compliance with the ethics committee approval. All participants in the study were physically examined by a specialist. After physical examination, all participants were informed regarding the study.

Table 1. Morphometric body measurements, age and training years of the participants in the study (Mean $\pm \mathrm{SD})$

\begin{tabular}{|c|c|c|c|c|}
\hline \multirow{3}{*}{ Features } & \multicolumn{4}{|c|}{ Groups } \\
\hline & \multicolumn{2}{|c|}{ Men } & \multicolumn{2}{|c|}{ Women } \\
\hline & $\begin{array}{l}\text { MO-sW (n } \\
25)\end{array}$ & Control (n 25) & $\begin{array}{r}\text { WO-sW (n } \\
25)\end{array}$ & Control (n 25) \\
\hline Age (year) & $18,00 \pm 1.63$ & $18.48 \pm 0,96$ & $18,16 \pm 0,74$ & $18,36 \pm 0,75$ \\
\hline Height $(\mathrm{cm})$ & $174.60 \pm 4,68$ & $173,00 \pm 6,28$ & $160,96 \pm 6,63$ & $162,96 \pm 5,04$ \\
\hline Body weight (kg) & $77,00 \pm 10,61$ & $73,12 \pm 8,93$ & $58,08 \pm 8,73$ & $57,48 \pm 7,89$ \\
\hline BMI $\left(\mathrm{kg} / \mathrm{m}^{2}\right)$ & $25,23 \pm 3,23$ & $24,10 \pm 2,75$ & $22,48 \pm 2,91$ & $21,59 \pm 2,35$ \\
\hline Training years & $4,5 \pm 1,3$ & - & $4,5 \pm 1,47$ & - \\
\hline
\end{tabular}

Ultrasonographic QFT images from both knees of all participants were taken by a specialist radiologist. Participants were placed supine with a 5 inch-diameter styrofoam roller behind the popliteal fossa for standardization of leg positioning. The superior pole of the patella was palpated and a Siemens acuson X 300 (Germany) US machine with an electronic $10 \mathrm{MHz}$ linear transducer (VF10-S) was used to visualize the QFT at its patellar insertion. The tendon was traced proximally to the musculotendinous junction of the rectus femoris and the extended view function was used to visualize the entire QFT. QFTT was measured in the middle part of the tendon. Any pathologic changes in the tendons were registered on a standard form. All clearly defined hypoechoic areas seen in both longitudinal and transverse ultrasound scans were registered as pathologic, regardless of the size of the area. Tendon thickness was measured $3 \mathrm{~cm}$ proximal to the superior pole of the patella (Figure 1). This process was then repeated for the other leg of the participant. Whether a pain exists on refractory knee extension was evaluated during physical examination by the specialist. Moreover, palpation and sensitivity evaluation of QFT was also evaluated. 


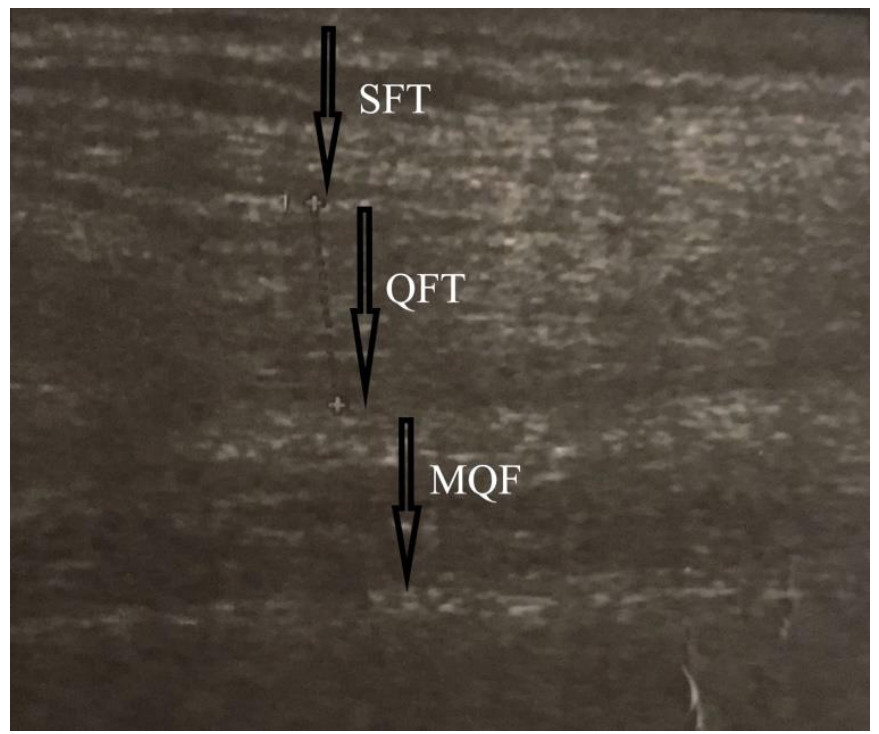

Figure 1. Quadriceps tendon ultrasound thickness measurement $3 \mathrm{~cm}$ proximal to the superior pole of patella. SFT (Subcutaneous fat tissue), QFT (quadriceps femoris tendon), MQF (m. quadriceps femoris)

\section{Statistical Analysis}

SPSS 23.0 software was used for the statistical analysis of the study data. Unpaired t test was used to analyze age, height, body weight, body mass index and training years of the groups. To evaluate other parameters, a non-parametric test, Mann-Whitney U test was preferred. Pearson Correlation parameter was also used to explain QFT measurements and age, height, body weight, body mass index and training years of the groups.

\section{Results}

A total of 100 individuals were enrolled in the study; there were 50 men and 50 women. A total of 200 QFTT was measured.

Table 2 shows right, left and mean QFTT measurements of the Olympic-style weightlifters and control groups.

We found that right-left and mean QFTT of the athletes was quantitively higher than right-left and mean QFTT of sedentary individuals. We also observed that QFTT of WO-sW was quantitively higher than QFTT of men in control group.

Table 2. Right-left and mean QFTT of the Olympic-style weightlifters and control groups (cm)

\begin{tabular}{rcccc}
\hline GROUPS & & Right QFTT & Left QFTT & Mean QFTT \\
\hline \multirow{2}{*}{ MO-sW (n 25) } & Mean &, 956 &, 956 &, 956 \\
& Std. Deviation &, 2417 &, 2417 &, 242 \\
\hline \multirow{2}{*}{ Control (n 25) } & Mean &, 644 &, 636 &, 640 \\
\hline \multirow{2}{*}{ WO-sW (n 25) } & Std. Deviation &, 1003 &, 1036 &, 101 \\
\hline \multirow{2}{*}{ Control (n 25) } & Mean &, 724 &, 724 &, 724 \\
\hline
\end{tabular}

QFTT: Quadriceps femoris tendon thickness

Right-left and mean QFTT measurements of the study groups are given in Table 3. It was found that right-left and mean QFTT measurements of MO-sW and WO-sW were higher than QFTT measurements of control groups ( $\mathrm{p}<0,001)$. 
Table 3. The comparison of right-left and mean QFTT measurements of MO-sW, WO-sW and control groups

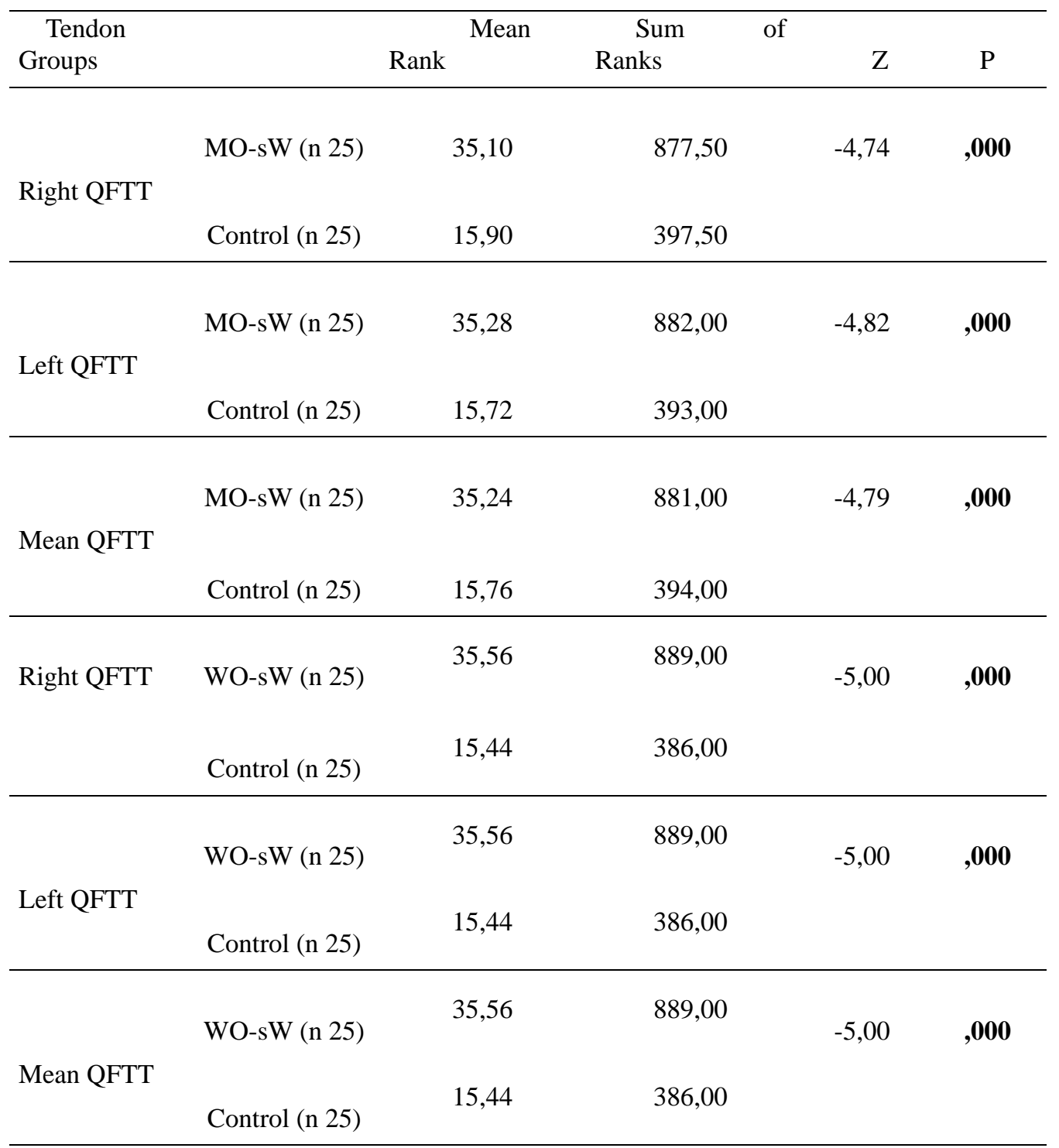

QFTT: Quadriceps femoris tendon thickness, $\mathrm{p}<0,001$

Pearson Correlation parameter was used to analyze QFTT variables and age, height, body weight, body mass index and training years data of the MO-sW and WO-sW with control groups. According to the analysis, there was a significant correlation $(\mathrm{p}<0,05)$ between body weight, body mass index and right-left and mean QFTT measurements of the MO-sW and WO-sW. Apart from the body weight and body mass index parameters of MO-sW and WO-sW, no statistically significant correlation was found between the other parameters of the groups. 
Table 4. The correlation between right-left-mean QFTT measurements and age, height, body weight, body mass index and training years of the groups

\begin{tabular}{|c|c|c|c|c|c|c|c|}
\hline \multirow{2}{*}{ Features } & & \multicolumn{3}{|c|}{ MO-sW $(n=25)$} & \multicolumn{3}{|c|}{ WO-sW $(n=25)$} \\
\hline & & $\begin{array}{l}\text { Right } \\
\text { QFTT }\end{array}$ & $\begin{array}{l}\text { Left } \\
\text { QFTT }\end{array}$ & $\begin{array}{l}\text { Mean } \\
\text { QFTT }\end{array}$ & \begin{tabular}{|l} 
Right \\
QFTT \\
\end{tabular} & $\begin{array}{l}\text { Left } \\
\text { QFTT }\end{array}$ & $\begin{array}{l}\text { Mean } \\
\text { QFTT }\end{array}$ \\
\hline \multirow{2}{*}{ Age (years) } & Pearson Correlation & ,232 &, 232 & ,232 &, 245 &, 245 &, 245 \\
\hline & $\mathrm{P}$ & ,264 &, 264 & ,264 &, 237 &, 237 &, 237 \\
\hline \multirow{2}{*}{ Height $(\mathrm{cm})$} & Pearson Correlation &, 213 & 213 &, 213 & ,096 & ,096 & ,096 \\
\hline & $\mathrm{p}$ & ,306 & ,306 & ,306 & ,648 & ,648 & ,648 \\
\hline \multirow{2}{*}{ Body Weight (kg) } & Pearson Correlation &, $583^{* * *}$ &, $583^{* *}$ &, $583^{* * *}$ &, $539^{* *}$ &, $539^{* *}$ &, $539^{* *}$ \\
\hline & $\mathrm{p}$ &, 002 & ,002 & ,002 & ,005 &, 005 &, 005 \\
\hline \multirow{2}{*}{ BMI $\left(\mathrm{kg} / \mathrm{m}^{2}\right)$} & Pearson Correlation &, $531^{* *}$ &, $531^{* *}$ &, $531^{* *}$ &, $560^{* *}$ &, $560^{* *}$ &, $560^{* *}$ \\
\hline & $\mathrm{p}$ &, 006 & ,006 &, 006 &, 004 &, 004 &, 004 \\
\hline \multirow{4}{*}{ Training years } & Pearson Correlation & ,094 & ,094 &, 094 &, 053 &, 053 &, 053 \\
\hline & $\mathrm{p}$ & ,656 & ,656 &, 656 & ,801 &, 801 &, 801 \\
\hline & 25) & \multicolumn{6}{|c|}{ Control (men= } \\
\hline & Pearson Correlation & ,204 &, 028 &, 116 &, 138 &, 042 &, 090 \\
\hline Age (years) & $\mathrm{p}$ & ,329 & ,893 &, 582 &, 511 &, 842 & ,670 \\
\hline \multirow{2}{*}{ Height $(\mathrm{cm})$} & Pearson Correlation &, 112 &, 147 &, 131 & ,279 & ,318 & ,301 \\
\hline & $\mathrm{p}$ &, 593 &, 483 &, 532 &, 176 &, 121 &, 144 \\
\hline \multirow{2}{*}{ Body Weight (kg) } & Pearson Correlation &, 234 & ,248 & ,243 &, 343 & ,338 & ,342 \\
\hline & $\mathrm{p}$ & ,261 &, 232 &, 241 & ,093 & ,099 & ,094 \\
\hline \multirow{2}{*}{ BMI $\left(\mathrm{kg} / \mathrm{m}^{2}\right)$} & Pearson Correlation & ,294 & ,328 & ,314 & ,261 & ,231 & ,247 \\
\hline & $\mathrm{p}$ &, 153 &, 110 &, 126 & ,207 &, 266 & ,234 \\
\hline
\end{tabular}

BMI: Body muscle index, QFTT: Quadriceps femoris tendon thickness $* * \mathrm{p}<0,001$

\section{Discussion}

In our study, we analyzed QFTT of O-sW athletes and sedentary individuals by using ultrasonographic imaging. We found no correlation between QFT of the groups and parameters of age, height and training years. In former studies to analyze the correlation between QFTT and demographic data, the researchers proposed varying arguments. In their study to measure QFTT by US images, Todd et al. (2015) reported that QFTT significantly changed with the increase in age, height and body weight, whereas, Özcakar et al. (2003) reported that a positive correlation was present in QFTT and body weight of highly skilled male footballers. Schweitzer et al. (1993) reported that QFTT increased with the increase in body weight of both men and women groups and that QFTT increased in women groups by age, while Teber M. et al. (2015) reported that there was no correlation between QFTT measurements and body mass index of the study groups.

In the study, we examined 200 QFTT measurements of our study and control groups. We found a sole correlation between QFTT measurements and body weight and body mass index parameters of MO-sW and WO-sW. No significant correlation was found in other parameters of the groups. A constraint to be noted while commenting the findings of our study was that owing to the limited number of international MO-sW and WO-sW, the extension of our study sample was also limited. We estimate that a larger study sample might enable a better analysis of the findings regarding the parameters such as age, height and training years. From this viewpoint, it's likely to mention that future studies on QFTT measurements with MO-sW and WO-sW including more athletes and different age groups might be useful.

The studies including QFTT measurement analysis of cadavers, unhealthy individuals and sedentary individuals have had various results. It was reported in these studies that mean QFTT of cadavers with mean age (80 years) was $0,60 \mathrm{~cm}$ (Damien et al. 2015), QFTT of child groups with skeletally immature (16 years) was 0,40 cm (Todd et al. 2015), QFTT of adult groups with skeletally immature (34,9 years) was $7,37 \mathrm{~cm}$ (Xerogeanes et al. 2013), mean QFTT (for both right and left knees) of men and women patients with kidney disorders was $0,49 \mathrm{~cm}$ and it was $0,54 \mathrm{~cm}$ in control groups (Teber M et al. 2015). 
In studies with QFTT measurements of athletes from different branches of sports, right QFTT was 6,84 mm and left QFTT was $6,83 \mathrm{~mm}$ in highly skilled male footballers (age18-31, height $1.81 \mathrm{~m}$, body weight $76.12 \mathrm{~kg}$ ) (Özçakar et al. 2003), for the professional beach volleyball players (male age 29.6; female age 27.1) QFTT of dominant foot was 6,9 $\mathrm{mm}$ and QFFT of non-dominant foot was 7,1 mm (Pfirrmann et al. 2008). Moreover, for highly skilled young volleyball players, right-left QFFT of women was 0,64 cm (age16,8, height $171 \mathrm{~cm}$, body weight $65 \mathrm{~kg}$ ) and right-left QFTT of men was $0,72 \mathrm{~cm}$ (age 17, height $184 \mathrm{~cm}$, body weight 72,5 kg) (Visnes et al. (2014). Mean QFTT of highly skilled men (age 26,83, height 1,81 cm, body weight $76,92 \mathrm{~kg}$ ) and women (age 27,21, height 168,95 cm body, weight $63,5 \mathrm{~kg}$ ) fencing athletes was $0,60 \mathrm{~cm}$ (Giombini et al. 2013).

We observed that mean QFFT of MO-sW and WO-sW in our study was 0,95 and 0,72 cm, (respectively), while mean QFFT of sedentary men and women individuals was 0,64 and 0,53 cm, (respectively). We realized that QFTT measurements of sedentary individuals in our study were very similar to the values with the study groups of Todd et al. (2015) and Damien et al. (2015). However, in the case of QFFT measurements of athletes, the QFTT measurements of MO-sW and WO-sW in our study were higher than those of athletes included in the studies of Özçakar et al. (2003), Pfirrmann et al. (2008), Visnes et al. (2014) and Giombini et al. (2013). In particular, the fact that QFTT of WO-sW in our study was higher than QFTT of men athletes in literature was notable. We consider that the observed differences result from sport branches of the groups and exercise diversity in trainings of these branches.

In the studies analyzing hypertrophic changes in QFTT depending on the trainings of the athletes, Visnes et al. (2014) reported that following heavy trainings, QFTT of highly skilled young volleyball players increased by 7 to $11 \%$ and Pfirrmann et al. (2008) observed hypertrophy in QFTT of beach volleyball players due to trainings and reported that resulting hypertrophic growth was related to anterior knee ache. Özçakar et al. (2003) reported that on both the right and left side separately, QFTT correlated positively with two types of jumping and sprint measurements.

In O-sW, the knee extensor muscles play an important role in the snatch and clean- and-jerk tasks. To perform these tasks, an athlete requires to lift the barbell from the floor to arm's length overhead and level with the shoulders, respectively, by full extension of the knee and hip joints (Garhammer 1991, 1993). Furthermore, O-sW an athlete to perform quick knee extensions and flexions. That's why, it might be assumed that the training regimen for the weightlifters, consisting mainly of the snatch and clean-and-jerk and their associated exercises, produces a greater training stimulus for quadriceps femoris muscles at the level proximal to the knee joint and this led the preferential hypertrophic growth in this region (Kanehisa et al. (2003).

In accordance with other studies in the literature, we estimate that trainings consisting of the snatch and clean-and-jerk and their associated exercises might have caused a hypertrophic change in QFT of the athletes in our study. In addition, after clinical and radiological assessment of the specialists, it was reported this hypertrophy change had no adverse effects on the health of the athlete.

Consequently, we found that owing to trainings in O-sW, the QFTT measurement of MO-sW and WO-sW were higher than that of sedentary individuals in our study. Furthermore, it's obvious that future studies are necessary to examine morphometric changes in QFT of O-sW athletes as well as the examination of force parameters in their QFT and to evaluate QFT effects on athletic feat of athletes.

\section{References}

Badıllo, J. J. G., Izquierdo, M., \& Gorostiaga, M. (2006). Moderate volume of high relative trainning intensity produces greater strenght gains compared with low and high volumes in competitive weightlifters. Journal of Strength and Conditioning Research, 20(1), 73-81. https://doi.org/10.1519/R-16284.1

Bencardino, J. T., Rosenberg, Z. S., Brown, R. R., Hassankhani, A., Lustrin, E. S., \& Beltran, J. (2000). Traumatic musculotendinous injuries of the knee: diagnosis with MR imaging.Radiographics, 20(1), 103-120, https://doi.org/10.1148/radiographics.20.suppl_1.g00oc16s103

Burdett, R. G. (1982). Biomechanics of the snatch technique of highly skilled and skilled weightlifters. Research Quarterly for Exercise and Sport, 53(3), 193-197. https://doi.org/10.1080/02701367.1982.10609339

Garhammer, J. (1991). A comparison of maximal power outputs between elite male and female weightlifters in competition. Int. J. Biomech, 7, 3-11. https://doi.org/10.1123/ijsb.7.1.3

Garhammer, J. (1993). A review of power output of Olympic and powerlifting: methodology, performance prediction, and evaluation tests. J Strength Cond Res 7(2), 76-89. https://doi.org/10.1519/00124278-199305000-00002

Garhammer, J., \& Takano, B. (1992). Training for weightlifting. Strength and power in sport, 3, 357-69. 
Giombini, A., Dragoni, S., Di Cesare, A., Di Cesare, M., Del Buono, A., \& Maffulli, N. (2013). Asymptomatic Achilles, patellar, and quadriceps tendinopathy: A longitudinal clinical and ultrasonographic study in elite fencers. Scand $J$ Med Sci Sports, 23(3), 311-316. https://doi.org/10.1111/j.1600-0838.2011.01400.x

Ilan, D. I., Tejwani, N., Keschner, M., \& Leibman, M. (2003). Quadriceps tendon rupture. J Am Acad Orthop Surg, 11(3), 192-200. https://doi.org/10.5435/00124635-200305000-00006

Kanehisa, H., Funato, K., Fukunaga, T., \& Katsuta, S. (2003). Growth trend of the quadriceps femoris muscle in junior Olympic weightlifters: an 18-month follow-up survey. Kanehisa, H., Funato, K., Kuno, S., Fukunaga, T., \& Katsuta, S. (2003). Growth trend of the quadriceps femoris muscle in junior Olympic weight lifters: an 18-month follow-up survey. European Journal of Applied Physiology, 89(3), 238-242. https://doi.org/10.1007/s00421-003-0802-x

Özçakar, L., Kunduracyoolu, B., Cetin, A., Ülkar, B., Guner, R., \& Hasçelik, Z. (2003). Comprehensive isokinetic knee measurements and quadriceps tendon evaluations in footballers for assessing functional performancen. British Journal of Sports Medicined, 37(6), 507-510. https://doi.org/10.1136/bjsm.37.6.507

Pfirrmann, C., Jost, B., Pirkl, C., Aitzetmüller, G., \& Lajtai, G. (2008). Quadriceps tendinosis and patellar tendinosis in professional beach volleyball players: sonographic findings in correlation with clinical symptoms. European Radiology, 18(8), 1703-1709. https://doi.org/10.1007/s00330-008-0926-9

Potage, D., Duparc, F., D'Utruy, A., Courage, O., \& Roussignol, X. (2015). Mapping the quadriceps tendon: an anatomic and morphometric study to guide tendon harvesting. Surgical and Radiologic Anatomy, 37(9), 10631067, https://doi:10.1007/s00276-015-1486-8. https://doi.org/10.1007/s00276-015-1486-8

Schweitzer, M., Mitchell, D., \& Ehrlich, S. (1993). The patellar tendon: thickening, internal signal buckling, and other MR variants. Skeletal Radiol, 22(6), 411-416. https://doi.org/10.1007/BF00538442

Staeubli, H. U., Bollmann, C., Kreutz, R., Becker, W., \& Rauschning, W. (1999). Quantification of intact quadriceps tendon, quadriceps tendon insertion, and suprapatellar fat pad: $\mathrm{m} \mathrm{r}$ arth rography, anatomy, and cryosections in the sagittal plane. American Journal of Roentgenology, 173(3), 691-698. https://doi.org/10.2214/ajr.173.3.10470905

Teber, M. A., Oğur, T., Bozkurt, A., Er, B., Turan, A., Gülbay, M., \& Akdağ, İ. (2015). Real-time Sonoelastography of the Quadriceps Tendon in Patients Undergoing Chronic Hemodialysis. Journal of Ultrasound in Medicine, 34(4), 671-677. https://doi.org/10.7863/ultra.34.4.671

Todd, D. C., Ghasem, A. D., \& Xerogeanes, J. W. (2015). Height, Weight, and Age Predict Quadriceps Tendon Length and Thickness in Skeletally Immature Patients. The American Journal of Sports Medicine, 43(4), 945-952. https://doi.org/10.1177/0363546515570620

Tuong, B., White, J., Louis, L., Cairns, R., Andrews, G., \& Forster, B. B. (2010). Get a kick out of this: the spectrum of knee extensor mechanism injuries. British Journal of Sports Medicine, 45(2), 140-146.

https://doi.org/10.1136/bjsm.2010.076695

Visnes, H., Tegnander, A., \& Bahr, R. (2014). Ultrasound characteristics of the patellar and quadriceps tendons among young elite athletes. Scandinavian Journal of Medicine \& Science in Sports, 25(2), 205-215. https://doi.org/10.1111/sms.12191

Walton, M., \& Rothwell, A. G. (1983). Reactions of thigh tissues of sheep to blunt trauma. Clin Orthop, 176, $273-281$. https://doi.org/10.1097/00003086-198306000-00040

Xerogeanes, J. W., Mitchell, P. M., Karasev, P. A., Kolesov, I. A., \& Romine, S. E. (2013). Anatomic and Morphological Evaluation of the Quadriceps Tendon Using 3-Dimensional Magnetic Resonance Imaging Reconstruction. The American Journal of Sports Medicine, 41(10), 2392-2399. https://doi.org/10.1177/0363546513496626

\section{Copyrights}

Copyright for this article is retained by the author(s), with first publication rights granted to the journal.

This is an open-access article distributed under the terms and conditions of the Creative Commons Attribution license which permits unrestricted use, distribution, and reproduction in any medium, provided the original work is properly cited. 